\title{
Клинико-иммунологические особенности профессионального бронхита
}

\author{
ГОУ ВПО "Самарский государственный медицинский университет Росздрава", Самара
}

\section{A.V.Zhestkov, V.V.Kosarev, S.A.Babanov, A.I.Kosov \\ Clinical and immunological features of occupational bronchitis}

\begin{abstract}
Summary
Based on results of investigation of 144 patients the authors described functional, bronchoscopic, microbiological, and immunological peculiarities of chronic dustrelated bronchitis and chronic toxico-chemical bronchitis.

\section{Резюме}

В статье на основании проведенных исследований описываются функциональные, бронхоскопические, микробиологические и иммунологические особенности хронического пылевого бронхита у 144 пациентов и хронического бронхита токсико-химической этиологии.
\end{abstract}

В настояшее время в условиях расширения промышленного производства наблюдается увеличение числа больных с различными формами профессиональной бронхолегочной патологии, в частности хроническим бронхитом. При этом известно, что хронический бронхит профессиональной - пылевой и токсикохимической - этиологии имеет свои особенности, отличные от клинико-функциональной и бронхоскопической картины при хронической обструктивной болезни легких, не связанной с воздействием профессиональных вредностей $[1,2]$.

Целью нашего исследования явилось изучение клинико-функциональных, бронхоскопических и иммунологических особенностей хронического бронхита профессиональной этиологии.

\section{Материалы и методы}

Нами проведен анализ клинико-функциональных показателей у 42 пациентов с хроническим пылевым бронхитом (ХПБ), 37 пациентов с бронхитом токсико-Химической этиологии (ХБТХЭ) и 65 человек из контрольной группы, профессиональная деятельность которых не была сопряжена с аэрозольными факторами риска (все они не имели заболеваний легких, хронических заболеваний других органов и систем и, по данным клинического обследования, были признаны здоровыми).

Обследованные больные всех групп находились в возрасте от 40 до 59 лет. Для изучения состояния легочного рисунка, его сосудистого и интерстициального компонентов среди рабочих пылеопасных производств проводилась стандартная рентгенография органов грудной полости. Бронхоскопическое исследование выполняли при помощи бронхоскопа FB-3C Olympus (Япония) с применением местной анестезии (1\%-й раствор лидокаина). Вентиляцион- ную функцию легких изучали посредством компьютерного пневмотахографа Custo Vit (Германия).

Микрофлора бактериального содержимого исследовалась до начала антимикробной химиотерапии. Идентификация бактериальной флоры при хроническом бронхите осуществлялась с использованием микробиологических методов (бактериоскопическое, бактериологическое исследование мокроты). Забор первичного материала осуществляли в соответствии с требованиями национальных стандартов [3-5]. Диагностический бронхоальвеолярный лаваж (БАЛ) проводили по щадящей методике с учетом рекомендаций Европейского респираторного общества $[3,5]$.

Показатели иммунного статуса определяли в соответствии с рекомендациями Всемирной организации здравоохранения и национальными руководствами. Методы исследования включали определение субпопуляций лимфоцитов с помощью моноклональных антител серии ЛТ, вычисление процента общей популяции клеток, экспрессирующих маркеров $\mathrm{CD} 3+$, CD4+, CD8+, CD16+, CD19+, CD25+, CD95+, а также HLA-DR+-лимфоцитов. Одновременно проводили клинический анализ крови для определения абсолютного количества клеток.

Содержание иммуноглобулинов A, M, G в сыворотке выявляли методом Манчини (радиальная иммунодиффузия). Для оценки состояния нейтрофилов периферической крови использовали латекс производства Института биологического приборостроения (Россия), устанавливали процент клеток, фагоцитирующих частицы. Гемолитическую активность комплемента СН50 и миелопероксидазы определяли с помощью стандартных реакций. Уровни цитокинов - интерлейкинов $1 \alpha, 1 \beta$ и 8 (IL- $1 \alpha$, IL- $1 \beta$, IL-8), фактора некроза опухоли $\alpha$ (TNF- $\alpha)$, интерферона (INF- $\gamma)$, общего иммуноглобулина E (IgE) 
и фибронектина в сыворотке крови определяли с помощью твердофазного иммуноферментного анализа.

\section{Результаты и обсуждение}

Было выявлено, что при профессионально обусловленных формах бронхита часто встречался хронический ринофарингит. Так, при хроническом пылевом бронхите поражение верхних дыхательных путей выявлено у 13 (30,95\%) пациентов, при хроническом бронхите токсико-химической этиологии у 18 (48,64 \%). Такая широкая распространенность патологии верхних дыхательных путей свидетельствует, прежде всего, о нисходящем характере процесса и подтверждает профессиональный характер основного заболевания [2]. При рентгенологическом исследовании выявляются пневмосклеротические и эмфизематозные изменения (табл. 1).

Фибробронхоскопия была выполнена у 42 пациентов с ХПБ, 37 пациентов с ХБТХЭ. При бронхоскопическом исследовании у больных ХПБ преобладали субатрофические и атрофические изменения слизистой оболочки трахеи и бронхов, которые проявлялись следующими признаками: ее истончением и бледно-розовым цветом, заостренностью карины бифуркации трахеи и шпор бронхов, подчеркнутостью устьев бронхиальных желез и хрящевого скелета. У 9 человек повышена складчатость слизистой оболочки бронхов, преимущественно в верхних долях, у них же обнаружены диффузное усиление сосудистого рисунка и явления гиперсекреции. Секрет слизистый, вязкий, располагается пристеночно, иногда с обтурацией просвета бронхов. В 5 случаях участки слизистой содержали пылевые включения.

Посредством фибробронхоскопии у 37 больных ХБТХЭ установлено наличие воспалительного процесса различной степени интенсивности и, как правило, двухсторонней локализации на фоне трахеобронхиальной дискинезии. Явления атрофических изменений в слизистой оболочке бронхов отмечались во всех $100 \%$ случаев.

При исследовании функции внешнего дыхания установлено, что форсированная жизненная емкость легких (ФЖЕЛ) была достоверно снижена по сравнению с контролем при ХПБ и ХБТХЭ $(p<0,001)$. Объем форсированного выдоха за 1-ю с $\left(\mathrm{OФB}_{1}\right)$ и индекс Тиффно (ОФВ / ФЖЕЛ) также были достоверно снижены в обеих группах обследуемых по сравнению с контрольной $(p<0,001)$.

Пиковая скорость выдоха (ПСВ) была достоверно снижена при ХПБ и ХБТХЭ $(p<0,001)$. Мгновенная объемная скорость после выдоха $25 \%$ ФЖЕЛ на уровне мелких бронхов $\left(\mathrm{MOC}_{25}\right)$ в обеих исследуемых группах также была достоверно снижена $(p<0,001)$. $\mathrm{MOC}_{50}$ и $\mathrm{MOC}_{75}$ с высокой достоверностью снижены во всех основных группах обследуемых пациентов $(p<0,001)$. Вязкостное дыхательное сопротивление (ВДС) при ХПБ и ХБТХЭ было повышено $(p<0,001)$.

Таким образом, в целях ранней диагностики гиперреактивности бронхов у лиц, контактирующих на производстве с промышленными аэрозолями, и определения степени функциональных нарушений при ХПБ и ХБТХЭ необходимо оценивать такие показатели форсированного выдоха, как ОФВ 1 , ФЖЕЛ, $\mathrm{OФВ}_{1} /$ ФЖЕЛ, ПСВ, $\mathrm{MOC}_{25}, \mathrm{MOC}_{50}, \mathrm{MOC}_{75}$ и ВДС. Колебания их значений могут служить первичным физиологическим маркером преморбидных изменений при хронической бронхолегочной патологии и должны использоваться при диспансерном наблюдении пациентов с заболеваниями легких профессиональной этиологии.

Из элиминационных механизмов в процессе иммунного ответа нами были изучены фагоцитарная активность лейкоцитов (ФАЛ), отражающая фазу поглощения чужеродных частиц, уровень фибронектина, способствующего синтезу коллагеновых волокон в легочной ткани и развитию фиброза, а также активность миелопероксидазы лимфоцитов, характеризующей кислородную фазу фагоцитоза, в течение которой происходит киллинг захваченных микроорганизмов и пылевых частиц.

Уровень ФАЛ при ХПБ и ХБТХЭ был снижен $(p<0,001)$, что свидетельствует о главенствующей роли нарушений фагоцитоза наравне с дисбалансом клеточных факторов в патогенезе профессиональных заболеваний органов дыхания. При ХПБ и ХБТХЭ выявлено достоверное увеличение уровня миелопероксидазы в сравнении с контрольной группой $(p<0,001)$. Миелопероксидаза, относящаяся $\mathrm{K}$ лизосомальным ферментам, обладает антимикробным действием, повышение ее активности ведет к повреждению бронхов и легких, нарушению бронхиальной проходимости.

Отмечается также значительное повышение сывороточного уровня фибронектина, который может служить биомаркером воспаления при ХПБ ( $p<0,001)$, менее значимо это показатель увеличен при ХБТХЭ $(p=0,003)$. Рост уровня фибронектина, по всей видимости, обусловлен тем, что первичная реакция альвеолярных макрофагов на инородные частицы всегда сопровождается усилением синтеза фибронектина, являющегося хемотаксическим фактором для фибробластов, а также универсальным опсонином.

Таблица 1

Клинические признаки, выявленные при хроническом бронхите

\begin{tabular}{l|c|c|c|c}
\multirow{2}{*}{\multicolumn{1}{c|}{ Группы }} & \multicolumn{4}{|c}{ Признаки } \\
\cline { 2 - 5 } & $\begin{array}{c}\text { Хронический } \\
\text { ринофарингит }\end{array}$ & $\begin{array}{c}\text { Субатрофические и атрофические } \\
\text { изменения слизистой }\end{array}$ & Пневмосклеро3 & Эмфизема легких \\
\hline ХПБ $(n=42)$ & $30,95 \%$ & $100 \%$ & $66,67 \%$ & $64,29 \%$ \\
\hline ХБТХЭ $(n=37)$ & $48,64 \%$ & $100 \%$ & $86,47 \%$ & $59,46 \%$ \\
\hline
\end{tabular}


Таблица 2

Иммунологические показатели при ХПБ и ХБХТЭ

\begin{tabular}{|c|c|c|c|}
\hline \multirow[t]{2}{*}{ Показатели } & ХПБ $(n=21)$ & ХБТХЭ $(n=17)$ & Контрольная группа ( $n=65)$ \\
\hline & $X \pm S$ & $X \pm S$ & $X \pm S$ \\
\hline Лейкоциты, абс., 109/л & $6,34 \pm 0,72^{\star * *}$ & $6,42 \pm 0,66^{\star * *}$ & $4,49 \pm 0,79$ \\
\hline Лимфоциты, абс., 109/л & $2,50 \pm 0,27^{\star \star *}$ & $2,53 \pm 0,28^{* * *}$ & $2,14 \pm 0,45$ \\
\hline Лимфоциты, \% & $31,67 \pm 2,69^{* * *}$ & $31,71 \pm 3,14^{\star * *}$ & $23,60 \pm 4,11$ \\
\hline CD3+, абс., $10^{9} / л$ & $1,54 \pm 0,30$ & $1,66 \pm 0,32$ & $1,49 \pm 0,35$ \\
\hline CD3+, \% & $66,52 \pm 3,93^{\star * *}$ & $65,82 \pm 3,92^{* * *}$ & $71,37 \pm 4,21$ \\
\hline CD4+, абс., $10^{9} / л$ & $0,86 \pm 0,14^{\star \star \star}$ & $0,89 \pm 0,17^{\star \star *}$ & $1,32 \pm 0,35$ \\
\hline $\mathrm{CD} 4+, \%$ & $40,71 \pm 2,61^{* * *}$ & $40,41 \pm 2,81^{* * *}$ & $45,08 \pm 3,09$ \\
\hline CD8+, абс., $10^{9} / л$ & $0,65 \pm 0,11$ & $0,63 \pm 0,13$ & $0,59 \pm 0,21$ \\
\hline $\mathrm{CD} 8+, \%$ & $32,19 \pm 2,46^{\star * *}$ & $32,59 \pm 2,37^{* * *}$ & $25,98 \pm 2,64$ \\
\hline CD16+, абс., 109/л & $0,20 \pm 0,03$ & $0,13 \pm 0,03^{* *}$ & $0,22 \pm 0,10$ \\
\hline CD16+, \% & $19,43 \pm 2,66^{* *}$ & $14,24 \pm 1,75^{\star *}$ & $17,86 \pm 1,85$ \\
\hline CD19+, абс., 109/л & $0,49 \pm 0,13^{\star * *}$ & $0,47 \pm 0,07^{\star \star *}$ & $0,33 \pm 0,11$ \\
\hline CD19+, \% & $12,95 \pm 2,31^{* * *}$ & $12,76 \pm 1,89^{\star * *}$ & $10,15 \pm 1,29$ \\
\hline CD4+ / CD8+ & $1,38 \pm 0,40^{\star \star \star}$ & $1,51 \pm 0,52^{\star \star \star}$ & $2,63 \pm 1,46$ \\
\hline CD25+, абс., $10^{9} / \pi$ & $0,15 \pm 0,03^{\star * *}$ & $0,16 \pm 0,03^{\star * *}$ & $0,13 \pm 0,16$ \\
\hline CD25+, \% & $7,38 \pm 1,75^{\star * *}$ & $7,71 \pm 1,69^{\star \star *}$ & $3,91 \pm 0,95$ \\
\hline CD95+, абс., $10^{9} / л$ & $0,20 \pm 0,06$ & $0,25 \pm 0,05$ & $0,20 \pm 0,03$ \\
\hline CD95+, \% & $9,90 \pm 2,66$ & $12,41 \pm 1,77$ & $10,22 \pm 2,28$ \\
\hline HLA-DR+, абс., $10^{9} / л$ & $0,25 \pm 0,03^{\star * *}$ & $0,30 \pm 0,05^{\star \star \star}$ & $0,18 \pm 0,02$ \\
\hline HLA-DR+, \% & $15,57 \pm 2,68^{* * *}$ & $18,82 \pm 2,77^{* * *}$ & $10,46 \pm 1,82$ \\
\hline ФАЛ, \% & $43,76 \pm 5,25^{\star * *}$ & $53,41 \pm 3,89^{* * *}$ & $59,35 \pm 8,17$ \\
\hline Миелопероксидаза, \% & $59,38 \pm 3,28^{* * *}$ & $59,06 \pm 3,07^{\star * *}$ & $46,29 \pm 3,16$ \\
\hline Фибронектин, нг/мл & $392,29 \pm 38,80^{* * *}$ & $324,00 \pm 39,25^{\star * *}$ & $287,98 \pm 44,95$ \\
\hline $\lg A, r / ת$ & $2,36 \pm 0,31^{\star \star *}$ & $2,51 \pm 0,39^{* * *}$ & $1,82 \pm 0,13$ \\
\hline $\lg M, ~ г / л$ & $1,25 \pm 0,17^{*}$ & $1,41 \pm 0,11^{*}$ & $1,14 \pm 0,14$ \\
\hline $\lg G, r / ת$ & $11,71 \pm 1,56^{\star \star *}$ & $15,30 \pm 2,32^{* * *}$ & $14,53 \pm 2,18$ \\
\hline IgE, МЕд/мл & $178,90 \pm 26,86^{* * *}$ & $216,35 \pm 25,57^{* * *}$ & $72,18 \pm 25,80$ \\
\hline CH50, e. a. & $45,81 \pm 2,01^{* * *}$ & $50,97 \pm 2,45^{\star * *}$ & $50,05 \pm 1,36$ \\
\hline IL-8, пг/мл & $63,00 \pm 7,25^{* * *}$ & $24,29 \pm 2,93^{* * *}$ & $15,78 \pm 4,10$ \\
\hline INF- $\gamma$, пг/мл & $119,00 \pm 6,04^{* * *}$ & $196,59 \pm 11,40^{* * *}$ & $191,54 \pm 12,04$ \\
\hline IL-1 $\alpha$, пг/мл & $12,29 \pm 2,70^{* * *}$ & $13,65 \pm 2,55^{\star * *}$ & $0,00 \pm 0,00$ \\
\hline IL-1 $\beta$, пг/мл & $5,50 \pm 1,86^{* * *}$ & $7,12 \pm 2,34^{\star \star *}$ & $30,72 \pm 2,35$ \\
\hline TNF- $\alpha$, пг/мл & $24,14 \pm 3,57^{\star * \star}$ & $101,12 \pm 8,29 * * *$ & $46,02 \pm 4,40$ \\
\hline
\end{tabular}

Примечание: * - достоверность различий с показателями контрольной группы при $p<0,05 ;$ ** $-p<0,01 ;$ *** - p<0,001. СН50 - количество комплемента в сыворотке, вызывающее лизис 50 \% эритроцитов в стандартном комплемент-зависимом гемолитическом тесте; INF- $\gamma$ - интерферон $\gamma$, IL-1 $\alpha$ - интерлейкин $1 \alpha$, IL-1 $1 \beta$ - интерлейкин $1 \beta$, TNF- $\alpha$ - фактор некроза опухоли $\alpha$.

Уровень иммуноглобулина А (IgA) в сыворотке крови был повышен у пациентов с ХПБ и ХБТХЭ. Концентрация иммуноглобулина М (IgM) в сыворотке крови при ХПБ и ХБТХЭ также была увеличена $(p<0,001)$. Сывороточный уровень иммуноглобулина $\mathrm{G}(\mathrm{IgG})$ был снижен при ХПБ $(p<0,001)$ и не был изменен при ХБХТЭ. Обращает на себя внимание рост уровня общего иммуноглобулина E ( $\mathrm{IgE}$ в в сыворотке крови у всех обследованных групп пациентов до величин, характерных для аллергической сенсибилизации $(p<0,001)$, как представлено в табл. 2.

На наш взгляд, повышение уровня общего $\mathrm{IgE}$ при профессиональном бронхите связано с тем, что в последнее время в производственной среде все большее распространение получают промышленные аэрозоли сложного состава, содержащие, кроме диоксида кремния, различные полимерные смолы и химические вещества, обладающие раздражающим и сенсибилизирующим действием. При профессио- нальных заболеваниях легких формирование септического гранулематозного типа воспаления сопровождается перекрестным связыванием поливалентным промышленным аллергеном специфического $\mathrm{IgE}$, фиксированного на высокоафинных IgE-рецепторах 1-го типа. Это вызывает активацию тучных клеток и базофилов, которые индуцируют и поддерживают аллергическую реакцию в верхних и нижних отделах респираторного тракта с помощью IgE-зависимого механизма.

Нами было обнаружено снижение гемолитической активности комплемента СН50 (одним из его основных биологических эффектов является функция иммунного цитолиза мембран различного происхождения) при хроническом пылевом бронхите $(p<0,001)$. При ХПБ уровень IL-8 в сыворотке крови был увеличен в 3,99 раза $(p<0,001)$, при ХБТХЭ в 1,54 раза $(p<0,001)$. Известно, что IL-8 продуцируется моноцитами и макрофагами, выполняет роль 
индуктора острых воспалительных реакций, стимулирует адгезивные свойства и хемотаксис нейтрофилов. Полученные результаты объясняются, по всей видимости, тем, что при интенсивных и длительных воспалительных процессах в сыворотке крови накапливаются провоспалительные цитокины.

Сывороточная концентрация IFN- $\gamma$ снижена при ХПБ в 1,61 раза $(p<0,001)$. Замедление синтеза IFN- $\gamma$ свидетельствует о недостаточной эффективности клеточных факторов иммунитета, что может способствовать персистенции воспалительного процесса. Синтез IL-1 $\alpha$ ускоряется при профессиональных формах бронхита. Причем IL- $1 \alpha$ является внутрисекреторным, а его высокую концентрацию в крови можно расценить как маркер повреждения клеток, в первую очередь, эпителия бронхиальной слизистой, что характерно для профессиональных заболеваний легких.

При ХПБ и ХБТХЭ сывороточная концентрация IL-1 $\beta$ была снижена в 5,59 и 4,32 раза соответственно $(p<0,001)$, что является критерием малой активности (хронического течения) воспалительного процесса в легких. Уровень TNF- $\alpha$ в сыворотке крови при ХПБ был снижен в 1,91 раза $(p<0,001)$ и повышен при ХБТХЭ в 2,2 раза $(p<0,001)$. TNF- $\alpha$ продуцируется моноцитами и макрофагами, его низкая концентрация может быть связана с недостаточной стимуляцией макрофагальной защиты организма.

Чаще всего при обострении хронического бронхита из мокроты больных выделяли Streptococcus pneumoniae (в 45,24 \% случаев при ХПБ, в 36,84 \% при ХБТХЭ) и негемолитические стрептококки (в 16,67 \% случаев при ХПБ, в 26,32 \% - при ХБТХЭ), несколько реже встречалась Haemophilus influenzae (в 14,29 \% случаев при ХПБ, в 15,79 \% - при ХБТХЭ). Частота встречаемости других микроорганизмов (Moraxella catarrhalis, Neisseria spp., Enterococcus spp.) была незначительной.

Доля пациентов, из мокроты которых не были выделены возбудители, была незначительной $(28,57 \%$ - в группе ХПБ, 36,84 \% - в группе ХБТХЭ). В этом случае можно судить о неинфекционной (вызванной промышленными аэрозолями) природе персистенции бронхиального воспаления.

Кроме того, обращает на себя внимание, что при профессиональных формах бронхита чаще встречается моноинфекция, а не микробные ассоциации. В результате цитологического анализа жидкости БАЛ (ЖБАЛ) при ХПБ $(n=23)$ выявлено снижение содержания альвеолярных макрофагов до 65,92 \pm $1,76 \%$ ( $p<0,001)$, повышение концентрации нейтрофилов до $28,74 \% \pm 1,78 \%(p<0,001)$, рост содержания бронхиальных клеток до 9,0 $\pm 1,25 \%$ ( $p<0,001)$, недостоверное увеличение относительного уровня лимфоцитов и эозинофилов $(p>0,05)$.

При анализе ЖБАЛ у больных ХБТХЭ $(n=19)$ содержание альвеолярных макрофагов было снижено до $69,16 \pm 0,95 \%(p<0,001)$, уровень нейтрофилов повышен до 17,24 $\pm 0,87 \%$ ( $p<0,001)$, бронхиальных клеток - до 8,10 $\pm 1,23 \%(p<0,001)$. Кроме того, при ХБТХЭ максимально увеличено относительное содержание эозинофилов - до 7,53 \pm 0,42 \% $(p<0,001)$. Степень роста концентрации нейтрофилов при анализе ЖБАЛ, на наш взгляд, может служить критерием оценки выраженности воспалительных изменений при хроническом бронхите профессиональной этиологии.

\section{Заключение}

Профессиональные формы бронхита сопровождаются выраженными атрофическими изменениями в верхних дыхательных путях. При ХПБ ринофарингит выявлен у 30,95\%, при ХБТХЭ - у 48,64 \% обследованных. Широкая распространенность при профессиональных формах бронхита патологии верхних дыхательных путей свидетельствует о нисходящем характере процесса и подтверждает профессиональный генез патологии.

При фибробронхоскопическом исследовании профессиональные формы бронхита характеризуются наличием субатрофических и атрофических изменений слизистой оболочки бронхов при минимальной активности воспаления. При проведении пневмотахографии снижаются потоковые показатели форсированного выдоха, увеличивается ВДС.

При профессиональных формах бронхита выявлена незначительная обсемененность бронхиального дерева патогенными микроорганизмами. В 28,57 \% случаев при ХПБ и в 38,84 \% - при ХБТХЭ из мокроты не были выделены возбудители. Степень увеличения содержания нейтрофилов в ходе анализа клеточного состава ЖБАЛ может служить критерием оценки выраженности воспалительных изменений при ХПБ.

Биомаркерами воспалительной реакции респираторного тракта при профессиональном бронхите являются фагоцитарная активность лейкоцитов, уровни фибронектина, IL-8, и TNF- $\alpha$ в сыворотке крови. Тяжесть и индивидуальный прогноз состояния пациента определяются степенью выраженности иммунологических нарушений - дисбаланса клеточных факторов иммунитета и цитокинов.

Особенности клеточных и гуморальных факторов иммунитета, цитокинового профиля при ХПБ характеризуются повышением уровней CD25+-лимфоцитов, миелопероксидазы, фибронектина, IgA, IgM, общего IgE, IL- $1 \beta$, IL- 8 , снижением содержания CD4+-клеток, фагоцитарной активности лейкоцитов, гемолитической активности комплемента, уровней IL- $1 \beta$, INF- $\gamma$, TNF- $\alpha$ в сыворотке крови. При ХБТХЭ иммунологические изменения характеризуются ростом лейкоцитов, лимфоцитов, CD19+-, CD25+-, CD95+-клеток в периферической крови, активности миелопероксидазы, концентрации фибронектина, IgA, IgM, общего IgE, IL-1 $\alpha$, IL-8, TNF- $\alpha$, а также снижением содержания CD4+- и CD16+-лимфоцитов, фагоцитарной активности лейкоцитов, уровня IL- $1 \beta$ в сыворотке крови.

\section{Литература}

1. Зинченко В.А., Разумов В.В., Гуревич Е.Б. Профессиональная хроническая обструктивная болезнь легких 
